\title{
Indacenodithienothiophene-Based Ternary Organic Solar Cells
}

\author{
Nicola Gasparini ${ }^{*}$, Amaranda García-Rodríguez ${ }^{2}$, Mario Prosa ${ }^{3}$, Şebnem Bayseç ${ }^{2}$, \\ Alex Palma-Cando ${ }^{2}$, Athanasios Katsouras ${ }^{4}$, Apostolos Avgeropoulos ${ }^{4}$, Georgia Pagona ${ }^{5,6}$, \\ Vasilis G. Gregoriou ${ }^{5,6}$, Christos L. Chochos ${ }^{4,5}$, Sybille Allard ${ }^{2}$, Ulrich Scherf ${ }^{2}$, \\ Christoph J. Brabec ${ }^{1,7}$ and Tayebeh Ameri ${ }^{1 *}$
}

\begin{abstract}
'Institute of Materials for Electronics and Energy Technology (I-MEET), Friedrich-Alexander-University Erlangen-Nuremberg, Erlangen, Germany, ${ }^{2}$ Macromolecular Chemistry Group (buwmakro), Institute for Polymer Technology, BergischeUniversität Wuppertal, Wuppertal, Germany, ${ }^{3}$ Istituto per lo Studio dei Materiali Nanostrutturati (ISMN), Consiglio Nazionale delle Ricerche (CNR), Bologna, Italy, ${ }^{4}$ Department of Materials Science Engineering, University of loannina, Ioannina, Greece, ${ }^{5}$ Advent Technologies SA, Patras Science Park, Patra, Greece, ${ }^{6}$ National Hellenic Research Foundation (NHRF), Athens, Greece, ${ }^{7}$ Bavarian Center for Applied Energy Research (ZAE Bayern), Erlangen, Germany
\end{abstract}

\section{OPEN ACCESS}

Edited by:

Amlan J. Pal,

Indian Association for the

Cultivation of Science, India

Reviewed by:

Lau Sing Liong,

Universiti Tunku Abdul Rahman,

Malaysia

Praveen C. Ramamurthy, Indian Institute of Science, India

${ }^{*}$ Correspondence:

Nicola Gasparini

nicola.gasparini@fau.de;

Tayebeh Amer

tayebeh.ameri@fau.de

Specialty section:

This article was submitted

to Solar Energy,

a section of the journal Frontiers in Energy Research

Received: 04 August 2016 Accepted: 15 December 2016

Published: 13 January 2017

Citation:

Gasparini N, García-Rodríguez A, Prosa M, Bayseç Ş, Palma-Cando A,

Katsouras A, Avgeropoulos A,

Pagona G, Gregoriou VG, Chochos CL, Allard S, Scherf U,

Brabec CJ and Ameri T (2017) Indacenodithienothiophene-Based

Ternary Organic Solar Cells.

Front. Energy Res. 4:40.

doi: 10.3389/fenrg.2016.00040
One of the key aspects to achieve high efficiency in ternary bulk-hetorojunction solar cells is the physical and chemical compatibility between the donor materials. Here, we report the synthesis of a novel conjugated polymer (P1) containing alternating pyridyl[2,1,3] thiadiazole between two different donor fragments, dithienosilole and indacenodithienothiophene (IDTT), used as a sensitizer in a host system of indacenodithieno[3,2-b] thiophene,2,3-bis(3-(octyloxy)phenyl)quinoxaline (PIDTTQ) and [6,6]-phenyl $\mathrm{C}_{70}$ butyric acid methyl ester $\left(\mathrm{PC}_{7_{1}} \mathrm{BM}\right)$. We found that the use of the same IDTT unit in the host and guest materials does not lead to significant changes in the morphology of the ternary blend compared to the host binary. With the complementary use of optoelectronic characterizations, we found that the ternary cells suffer from a lower mobility-lifetime $(\mu \tau)$ product, adversely impacting the fill factor. However, the significant light harvesting in the near infrared region improvement, compensating the transport losses, results in an overall power conversion efficiency enhancement of $~ 7 \%$ for ternary blends as compared to the PIDTTQ:PC ${ }_{71} \mathrm{BM}$ devices.

Keywords: organic solar cells, ternary devices, OPV, IDTT, organic electronics

\section{INTRODUCTION}

During the last decades, the power conversion efficiency (PCE) of organic bulk-hetorojunction (BHJ) solar cells based on donor/acceptor blends surpassed the $10 \%$ threshold, mainly due to the discovery of novel materials as well as device structure engineering (Liu et al., 2014; He et al., 2015; Holliday et al., 2016; Huang et al., 2016; Spyropoulos et al., 2016; Zhao et al., 2016). Polymers and/ or small molecules, used as donor materials, in combination with fullerene derivatives, used as acceptor, are the common active components in BHJ devices (Zhang et al., 2014; Lu et al., 2015c; Min et al., 2015; Squeo et al., 2015). Due to the narrow absorption of the donor materials, one of the main challenges in order to further boost the PCE of organic solar cells is to achieve better absorption match to the solar irradiance spectrum. In this regard, two main concepts have been developed: tandem and ternary organic solar cells (Ameri et al., 2009, 2013a,b; Li et al., 2013; You et al., 2013; Spyropoulos et al., 2014; Lu et al., 2015b; Yang et al., 2015; Cheng et al., 2016; Goh et al., 2016; 
Keawsongsaeng et al., 2016; Lee et al., 2016; Nian et al., 2016). The former is based on a complex multi-layer stack with the main challenge of designing a robust solution-processed intermediate layer. The latter, made of two donors and one acceptor, mixed together in a unique solution, overcomes the complexities of the tandem device architecture, maintaining the easy processability of a single-junction organic BHJ solar cell. To date, polymers ( $\mathrm{Lu}$ et al., 2014, 2015a; Gasparini et al., 2015b; Yang et al., 2015), small molecules (Zhang et al., 2015), dyes (Ke et al., 2016), quantum dots (Itskos et al., 2011), and fullerene derivatives (Cheng et al., 2014) have been adopted as "guest" in the polymer-fullerene "host" system. In addition to the need for donor materials with the complementary absorption, one of the key points to surpass the performance of binary cells in ternary devices is to find donor materials with compatible physical and chemical nature (Yang et al., 2015). This can prevent the formation of recombination centers or morphological traps, which deteriorate the photovoltaic properties.

Here, we report a ternary organic solar cell system processed in air that shows a pronounced sensitization effect, resulting in a PCE of more than $4.6 \%$. As sensitizer, we incorporate the near infrared (NIR) polymer P1 containing alternating pyridyl $[2,1,3]$ thiadiazole between two different donor fragments, dithienosilole and indacenodithienothiophene (IDTT), into a host system of indacenodithieno[3,2-b] thiophene,2,3-bis(3(octyloxy)phenyl)quinoxaline (PIDTTQ) (Gasparini et al., 2015a) blended with [6,6]-phenyl $\mathrm{C}_{70}$ butyric acid methyl ester $\left(\mathrm{PC}_{71} \mathrm{BM}\right)$. Indeed, in order to have components with a similar chemical nature in the ternary blend system, we used two polymers with the same backbone IDTT unite for the host as well as the guest donors.

The polymer P1 was synthesized by Stille-type aromatic cross-coupling reaction of a stoichiometric balance ratio of the distannyl derivative of para-hexyl-phenyl substituted IDTT (M2) and 4,4'-(4,4-bis(2-ethylhexyl)-4H-silolo[3,2-b:4,5- $\left.b^{\prime}\right]$ dithiophene-2,6-diyl)bis(7-bromo-[1,2,5] thiadiazolo[3,4-c] pyridine) (M1), in the presence of tris(dibenzylideneacetone) dipalladium $(0)\left(\mathrm{Pd}_{2} \mathrm{dba}_{3}\right)$ and tri(o-tolyl)phosphine $\left(\mathrm{P}(o \text {-tol })_{3}\right)$ as the catalytic system (Scheme 1). After soxhlet extraction the polymer was obtained from the $o$-dichlorobenzene fraction with a number average molecular weight $\mathrm{Mn}$ of $36,800 \mathrm{~g} \mathrm{~mol}^{-1}$ and a polydispersity index of 3.3.

Figure S1 in Supplementary Material shows the absorption spectrum of P1 in DCB solution and as solid. The copolymer for both cases shows a single band in the high energy region, which is assigned to a localized $\pi-\pi^{*}$ transition and another absorption band in the low energy region (up to $1,000 \mathrm{~nm}$ ), which is assigned to an intramolecular charge-transfer transition. The maximum of the NIR absorption band of P1 in the solid state is bathochromic shifted $(738 \mathrm{~nm})$ in comparison to the corresponding UV-VIS solution $(695 \mathrm{~nm})$. The optical band gap energy estimated from the absorption edge of film spectrum was estimated to be $1.87 \mathrm{eV}$. Based on the onsets of the oxidation and reduction peaks in cyclic voltammetry $(\mathrm{CV})$ measurements, the electrochemical highest occupied molecular orbital (HOMO) and lowest unoccupied molecular orbital (LUMO) energies were estimated to be -5.34 and $-3.71 \mathrm{eV}$, respectively, corresponding to an electrochemical band gap energy of $1.63 \mathrm{eV}$ (Gedefaw et al., 2016).

Next, we analyzed the device performances of the ternary devices. The device architecture used in this work is based on ITO/ZnO/active layer/MoOx/Ag. PIDTTQ [its lower molecular weight version of PIDTTQ-LMW (Gasparini et al., 2015a)] has been previously presented in the literature. All the solutionprocessed layers are doctor bladed in air. Figure 1A depicts the energy levels, measured with $\mathrm{CV}$ of the polymers and the fullerene derivate. Figure 1C shows the current density-voltage characteristics of the binary PIDTTQ: $\mathrm{PC}_{71} \mathrm{BM}(1: 2 \mathrm{wt} / \mathrm{wt})$ as well as ternary PIDTTQ:P1:PC ${ }_{71} \mathrm{BM}$ (different composition) under 1 sun illumination $\left(100 \mathrm{~mW} \mathrm{~cm}^{-2}\right)$. In agreement with previous reports, binary cells delivered a PCE of $4.3 \%$ with an open circuit voltage $\left(V_{\text {oc }}\right)$ of $0.84 \mathrm{~V}$, a short circuit current $\left(J_{\mathrm{sc}}\right)$ of $8.62 \mathrm{~mA} \mathrm{~cm}^{-2}$, and a fill factor (FF) of $60 \%$. Adding $15 \mathrm{wt} \%$ of the NIR sensitizer delivers the highest short-circuit current, reaching $10.60 \mathrm{~mA} \mathrm{~cm}^{-2}, V_{\text {oc }}$ of $0.84 \mathrm{~V}$, and $\mathrm{FF}$ of $52 \%$, increases the overall efficiency of the ternary system $4.6 \%$ under 1 sun conditions. As shown in Table 1, $J_{\text {sc }}$ increased monotonically by increasing the amount of P1, due to the better harvesting of the ternary system in the NIR region, in the best case, an improvement in $J_{s c}$ of $\sim 20 \%$ is achieved in the ternary system PIDTTQ:P1:PC ${ }_{71} B M(0.85: 0.15: 2)$. Notably, the $V_{\text {oc }}$ obtained in the ternary cells is identical to the binary PIDTTQ:PC ${ }_{71} \mathrm{BM}$, reflecting an energy cascade between the HOMO and LUMO energy levels of the three components (Figure 1A). Unfortunately, we observed a continuously decreased in FF by introducing higher amount of P1, which indeed inhibits the higher improvements of the ternary device performance compared to its reference.
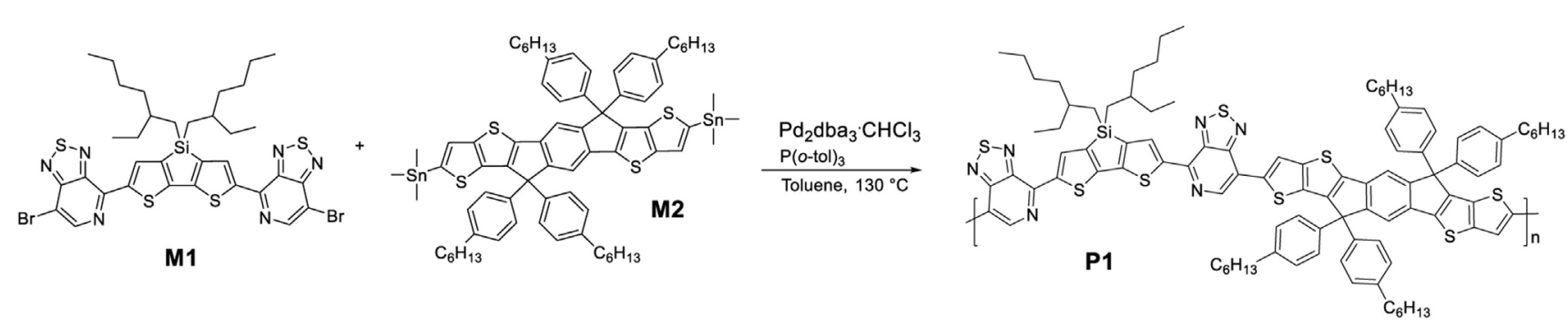

SCHEME 1 | Polymerization reaction toward the preparation of P1. 
A

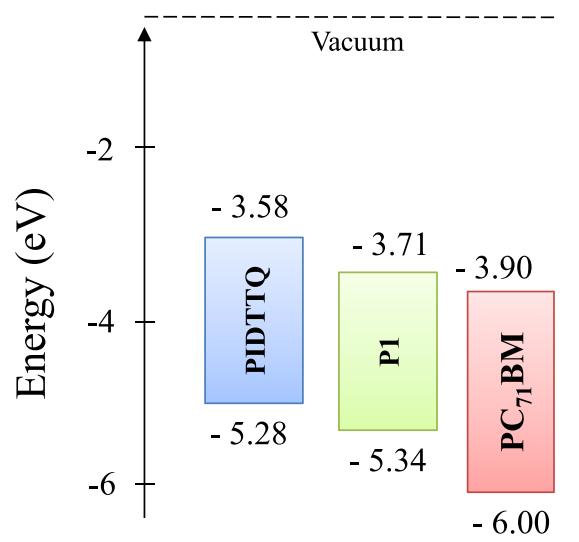

C

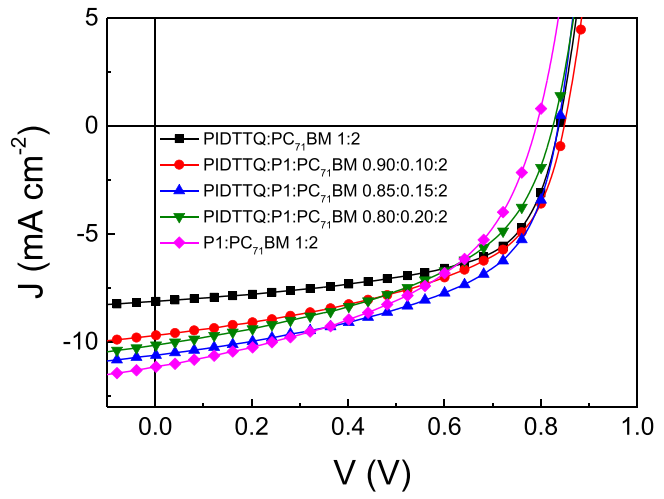

B

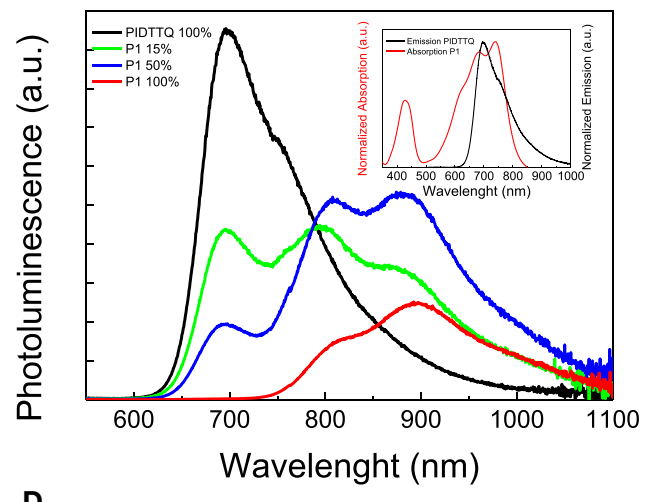

D

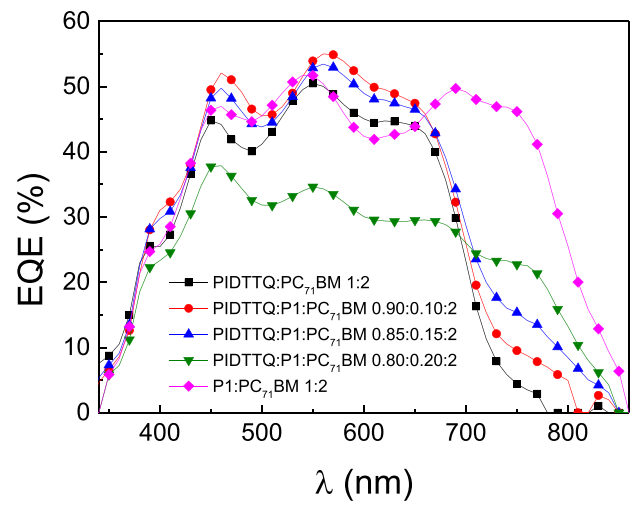

FIGURE 1 | (A) Energy diagram of the materials studied; (B) photoluminescence spectra of PIDTTQ (black), P1 (red) pristine films, and mixtures of PIDTTQ:P1 with 75:15 (green) and 50:50 (blue) weight ratio; (C) current density-voltage characteristics of binary and ternary-based solar cells under solar simulator illumination $\left(100 \mathrm{~mW} \mathrm{~cm}^{-2}\right)$; (D) external quantum efficiency curves of the same devices as shown in (C).

TABLE 1 | Photovoltaic device parameters of low, medium, and high molecular weight PIDTTQ-based inverted solar cells under 1 sun illumination (100 $\mathrm{mW} \mathrm{cm}^{-2}$ ).

\begin{tabular}{|c|c|c|c|c|}
\hline PIDTTQ:P1:PC ${ }_{71} B M$ & $V_{\text {oc }}(\mathrm{V})$ & $J_{\mathrm{sc}}\left(\mathrm{mA} \mathrm{cm} \mathrm{cm}^{-2}\right)$ & Fill factor (\%) & Power conversion efficiency (\%) \\
\hline $1: 0: 2$ & $0.84(0.84 \pm 0.01)$ & $8.62(8.49 \pm 0.23)$ & $60.33(59.72 \pm 0.65)$ & $4.32(4.24 \pm 0.10)$ \\
\hline 0.90:0.10:2 & $0.84(0.84 \pm 0.01)$ & $9.69(9.50 \pm 0.18)$ & $53.14(52.48 \pm 0.55)$ & $4.29(4.20 \pm 0.10)$ \\
\hline $0.85: 0.15: 2$ & $0.84(0.84 \pm 0.01)$ & $10.60(10.43 \pm 0.22)$ & $51.87(50.64 \pm 1.17)$ & $4.63(4.45 \pm 0.19)$ \\
\hline 0.80:0.20:2 & $0.84(0.84 \pm 0.01)$ & $10.14(9.64 \pm 0.44)$ & $48.86(48.64 \pm 0.20)$ & $4.04(3.86 \pm 0.17)$ \\
\hline $0: 1: 2$ & $0.81(0.81 \pm 0.01)$ & $10.87(10.37 \pm 0.41)$ & $46.61(45.57 \pm 0.69)$ & $3.95(3.79 \pm 0.10)$ \\
\hline
\end{tabular}

We further measured external quantum efficiency (EQE) spectra of OPV devices made from PIDTTQ:P1:PC $\mathrm{C}_{71} \mathrm{BM}$ and PIDTTQ:PC ${ }_{71} \mathrm{BM}$ (Figure 1D). Photoaction spectra of active layers with increasing P1 content show improved photoresponse particularly around $800 \mathrm{~nm}$, i.e., the enhancement in $J_{\mathrm{sc}}$ originates dominantly from the NIR polymer absorption regime. We note that the integrated $\mathrm{EQE}$ for these devices matches the measured short circuit current within a margin of $5 \%$.

In order to shine light into the mechanism, we performed photoluminescence (PL) measurements. PL is widely used in ternary $\mathrm{BHJ}$ solar cells to discriminate between energy and charge transfer between host and guest materials (Lu et al., 2014, 2015a; Gasparini et al., 2015b). In principle, if the charges are transfer from the wide to the low band gap material, the PL of the host should decrease while the PL of guest material should not increase. On the other hands, if the energy transfer is the main mechanism, a quenching of the host PL is associated with an increase of guest PL. Moreover, in order to have an energy transfer, the absorption of the guest polymer should overlap with the emission of the guest. The inset of Figure 1B confirms the aforementioned requirement. Thus, we mixed together PIDTTQ and $\mathrm{P} 1$ in different weight ratio. As depicted in Figure 1B, the PL of PIDTTQ is quenched of 53 and $79 \%$ upon introduction of P1 (85-15 and 50-50, respectively). In addition, we observed a clear 
enhancement of P1 PL compared to the pristine one, indicating an efficient energy transfer.

Before getting insight into the optical and electrical behavior of the binary and ternary devices, we performed intermittent contact mode atomic force microscopy (AFM, Figure 2). In agreement with our previous study (Gasparini et al., 2015a), the topography of PIDTTQ:PC ${ }_{71} \mathrm{BM}$ layer shows spherical features with domains of $\sim 100 \mathrm{~nm}$. Interestingly, we observed similar morphology for ternary active layers. We calculated a root mean square roughness of $0.46,0.51$, and $0.60 \mathrm{~nm}$ for PIDTTQ:PC ${ }_{71} \mathrm{BM}, \quad$ PIDTTQ:P1:PC ${ }_{71} \mathrm{BM} \quad(0.85: 0.15: 2)$ and $\mathrm{P} 1: \mathrm{PC}_{71} \mathrm{BM}$ blends, respectively. Thus, the low FF calculated for PIDTTQ:P1:PC ${ }_{71} \mathrm{BM}$ cannot be ascertained to changes in the microstructure upon addition of the guest sensitizer.

In order to understand the lower FF obtained in the ternary BHJ solar cells, we first studied the charge transport properties by employing the technique of photoinduced charge carrier extraction by linearly increasing voltage (photo-CELIV) (Mozer et al., 2005; Clarke et al., 2015; Min et al., 2015). From the measured photocurrent transients, the charge carrier mobility $(\mu)$ is calculated using the following equation:

$$
\mu=\frac{2 d^{2}}{3 A t_{\max }^{2}\left[1+0.36 \frac{\Delta j}{j(0)}\right]} \quad \text { if } \Delta j \leq j(0),
$$

where $d$ is the active layer thickness, $A$ is the voltage rise speed $A=d U / d t, U$ is the applied voltage, $t_{\max }$ is the time corresponding to the maximum of $\Delta j$ of the extraction peak, and $j(0)$ is the displacement current.

Figure $\mathbf{3 A}$ shows the transient recorded by applying a $2 \mathrm{~V} / 60 \mu$ s linearly increasing reverse bias and a delay time (td) of $10 \mu \mathrm{s}$. Analysis of the photo-CELIV traces extracts charge carrier
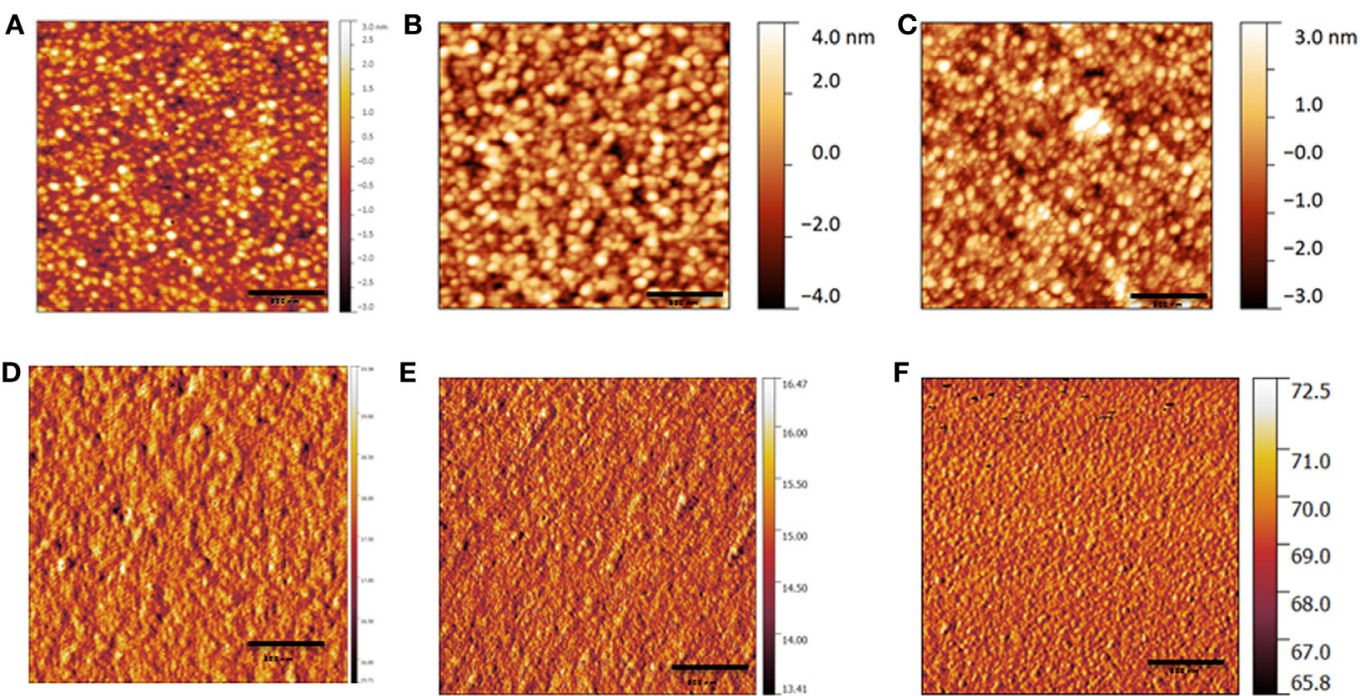

FIGURE 2 | Topography and phase images of films of PIDTTQ:PC ${ }_{71} B M$ (1:2) (A-D), PIDTTQ:P1:PC ${ }_{71} B M$ (0.85:0.15:2) (B-E), and P1:PC ${ }_{71} B M$ (1:2) (C-F) on top of a layer of $\mathrm{ZnO}$, as measured by intermittent contact mode atomic force microscopy.
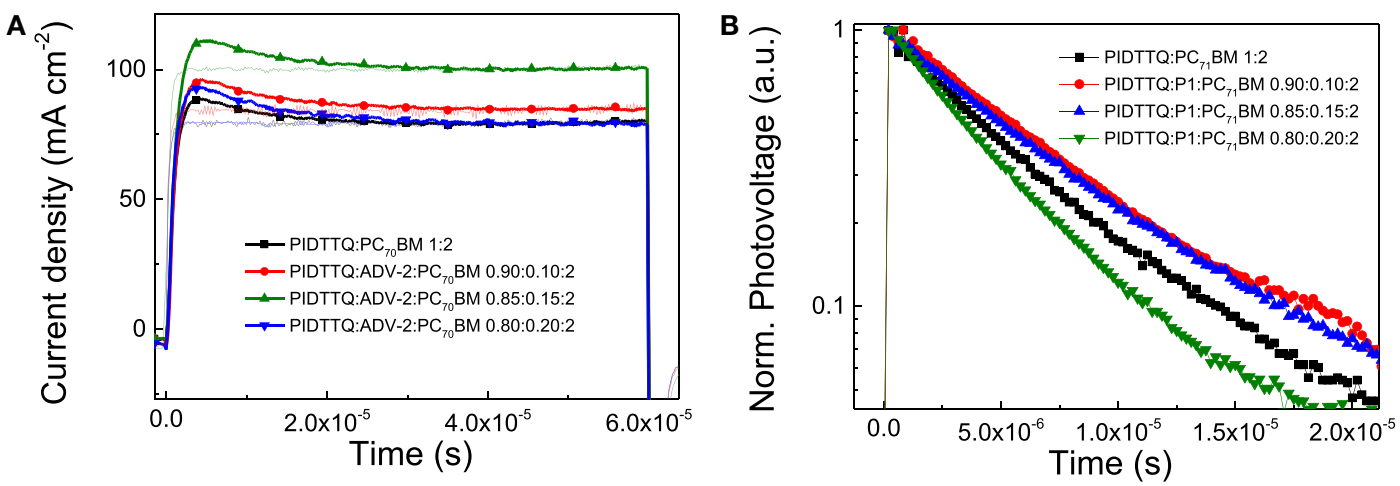

FIGURE 3 | Time-dependent photo-CELIV traces under light (solid lines) and dark (semitransparent traces) conditions (A) and transient photovoltage

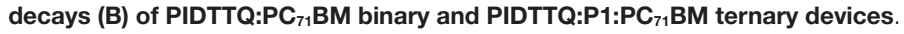


mobility values $1.13 \times 10^{-4} \mathrm{~cm}^{2} \mathrm{~V}^{-1} \mathrm{~s}^{-1}, 8.54 \times 10^{-5} \mathrm{~cm}^{2} \mathrm{~V}^{-1} \mathrm{~s}^{-1}$, $7.53 \times 10^{-5} \mathrm{~cm}^{2} \mathrm{~V}^{-1} \mathrm{~s}^{-1}$, and $7.42 \times 10^{-5} \mathrm{~cm}^{2} \mathrm{~V}^{-1} \mathrm{~s}^{-1}$ for PIDTTQ:PC ${ }_{71} \mathrm{BM}$ (1:2)-, PIDTTQ:P1:PC ${ }_{71} \mathrm{BM}$ (0.90:0.10:2)-, PIDTTQ:P1:PC ${ }_{71} \mathrm{BM} \quad$ (0.85:0.15:2)-, PIDTTQ:P1:PC ${ }_{71} \mathrm{BM}$ (0.80:0.20:2)-based devices, respectively. We also calculated the charge mobility of P1:PC71BM (Figure S5 in Supplementary Material), and we found a value of $5.02 \times 10^{-5} \mathrm{~cm}^{2} \mathrm{~V}^{-1} \mathrm{~s}^{-1}$. The lower FFs obtained in the ternary cells are in agreement with the lower charge carrier mobility calculated with photo-CELIV technique. We then analyze the lifetime of charge carriers by employing transient photovoltage technique (TPV) (Shuttle et al., 2008). The samples were connected to the terminal of an oscilloscope with the input impedance of $1 \mathrm{M} \Omega$ and illuminated with a continuous background laser to control the $V_{\mathrm{oc}}$. A small optical perturbation was applied using a blue laser $(\lambda=405 \mathrm{~nm})$. The pulse intensity was controlled to keep the height of the photovoltage transient smaller than $10 \mathrm{mV}$ resulting in a voltage transient with amplitude $\Delta V \ll V_{\text {oc }}$. The measured transient decays show the form of single exponentials, as expected for the pseudo-first-order kinetic (Hamilton et al., 2010; Heumueller et al., 2015).

$$
\frac{d \Delta V}{d t} \propto \frac{d \Delta n}{d t}=-k_{\text {eff }}=-\frac{\Delta n}{\tau_{\Delta n}},
$$

where $V$ is the photovoltage, $t$ is the time, $\Delta n$ is change in the density of photogenerated carriers due to the perturbation pulse, $k_{\text {eff }}$ is the pseudo-first order rate constant, and $\tau_{\Delta n}$ is the carrier lifetime. The Figure 3B depicts normalized photovoltage

TABLE 2 | Summary of calculated charge carrier mobility $(\mu)$, bimolecular lifetime $(\tau)$, mobility-lifetime product $(\mu \tau)$, and charge carrier concentration $(n)$ of binary and ternary devices.

\begin{tabular}{lcccc}
\hline PIDTTQ:P1:PC $\mathbf{7 1}^{\mathbf{1}} \mathbf{B M}$ & $\boldsymbol{\mu}\left[\mathbf{c m}^{\mathbf{2}} \mathbf{V}^{-\mathbf{1}} \mathbf{s}^{-\mathbf{1}}\right]$ & $\boldsymbol{\tau}[\mathbf{s}]$ & $\boldsymbol{\mu} \boldsymbol{\tau}\left[\mathbf{c m}^{\mathbf{2}} \mathbf{V}^{-\mathbf{1}}\right]$ & $\mathbf{n}\left[\mathbf{c m}^{-\mathbf{3}}\right]$ \\
\hline $1: 0: 2$ & $1.13 \times 10^{-4}$ & $6.72 \times 10^{-6}$ & $7.59 \times 10^{-10}$ & $2.97 \times 10^{16}$ \\
$0.90: 0.10: 2$ & $8.54 \times 10^{-5}$ & $7.35 \times 10^{-6}$ & $6.72 \times 10^{-10}$ & $3.02 \times 10^{16}$ \\
$0.85: 0.15: 2$ & $7.53 \times 10^{-5}$ & $7.23 \times 10^{-6}$ & $5.44 \times 10^{-10}$ & $3.66 \times 10^{16}$ \\
$0.80: 0.20: 2$ & $7.42 \times 10^{-5}$ & $4.72 \times 10^{-6}$ & $3.50 \times 10^{-10}$ & $1.15 \times 10^{16}$
\end{tabular}

decays as a function of time for the binary and ternary devices at 1 sun condition by exciting with a blue laser $(\lambda=405 \mathrm{~nm})$. As reported in Table 2, the lifetime of charge carriers is similar for PIDTTQ:PC ${ }_{71} \mathrm{BM}$ (1:2), PIDTTQ:P1:PC ${ }_{71} \mathrm{BM}$ (0.90:0.10:2), PIDTTQ:P1:PC ${ }_{71} \mathrm{BM} \quad(0.85: 0.15: 2), 6.72,7.35$, and $7.23 \mu \mathrm{s}$, respectively, suggesting that these ternary blends are not limited by the short lifetime of charge carriers. Otherwise, a reduce $\tau$ is observed for the PIDTTQ:P1:PC ${ }_{71} \mathrm{BM}(0.80: 0.20: 2)$ based ternary system $(4.72 \mu \mathrm{s})$. Thus, with the combination of photo-CELIV and TPV techniques, we were able to calculate the mobility-lifetime product $(\mu \tau)$. As collected in Table 2, $\mu \tau$ decreases from $7.59 \times 10^{-10} \mathrm{~cm}^{2} \mathrm{~V}^{-1}$ to $6.72 \times 10^{-10} \mathrm{~cm}^{2} \mathrm{~V}^{-1}$, $5.44 \times 10^{-10} \mathrm{~cm}^{2} \mathrm{~V}^{-1}$, and $3.50 \times 10^{-10} \mathrm{~cm}^{2} \mathrm{~V}^{-1}$ for PIDTTQ:PC ${ }_{71} \mathrm{BM}$ (1:2), PIDTTQ:P1:PC ${ }_{71} \mathrm{BM}$ (0.90:0.10:2), PIDTTQ:P1:PC ${ }_{71} \mathrm{BM}$ (0.85:0.15:2), PIDTTQ:P1:PC ${ }_{71} B M$ (0.80:0.20:2)-based devices, reason of the poorer transport properties in the ternary blends compared to the binary $\mathrm{BHJ}$ devices.

Understood the limitation in the transport properties, we then focus on the better ability of the ternary system in the photogeneration by employing charge extraction (CE) and photoinduced absorption (PIA) spectroscopy (Salvador et al., 2012; Löslein et al., 2013; Gasparini et al., 2015b). In CE measurements, the samples were connected to the terminal of an oscilloscope with the input impedance of $1 \mathrm{M} \Omega$ and illuminated with a continuous background laser to keep it in the $V_{\text {oc }}$ condition (Heumueller et al., 2015). In order to study the transient decay, we used a nanosecond switch that shifts the cell from open circuit to short circuit condition, allowing the calculation of charge density $(n)$ by integrating the curves, respectively (Figure 4A) (Heumueller et al., 2015; Gasparini et al., 2016). In agreement with the $J_{s c}$ values obtained, we calculate $n$ as $2.97 \times 10^{16} \mathrm{~cm}^{-3}, 3.02 \times 10^{16} \mathrm{~cm}^{-3}$, $3.66 \times 10^{16} \mathrm{~cm}^{-3}$, and $1.15 \times 10^{16} \mathrm{~cm}^{-3}$ for PIDTTQ:PC ${ }_{71} \mathrm{BM}$ (1:2), PIDTTQ:P1:PC ${ }_{71}$ BM (0.90:0.10:2), PIDTTQ:P1:PC ${ }_{71} B M$ (0.85:0.15:2), PIDTTQ:P1:PC ${ }_{71}$ BM (0.80:0.20:2) based devices, respectively (Table 2 ). The ability of charge generation in the $\mathrm{BHJ}$ solar cells is also studied with PIA spectroscopy. We employed steady-state and frequency-dependent PIA spectroscopy at a pump energy of $2.33 \mathrm{eV}$ to gain further insight into the underlying photophysical steps of the sensitization process. Figure 4B
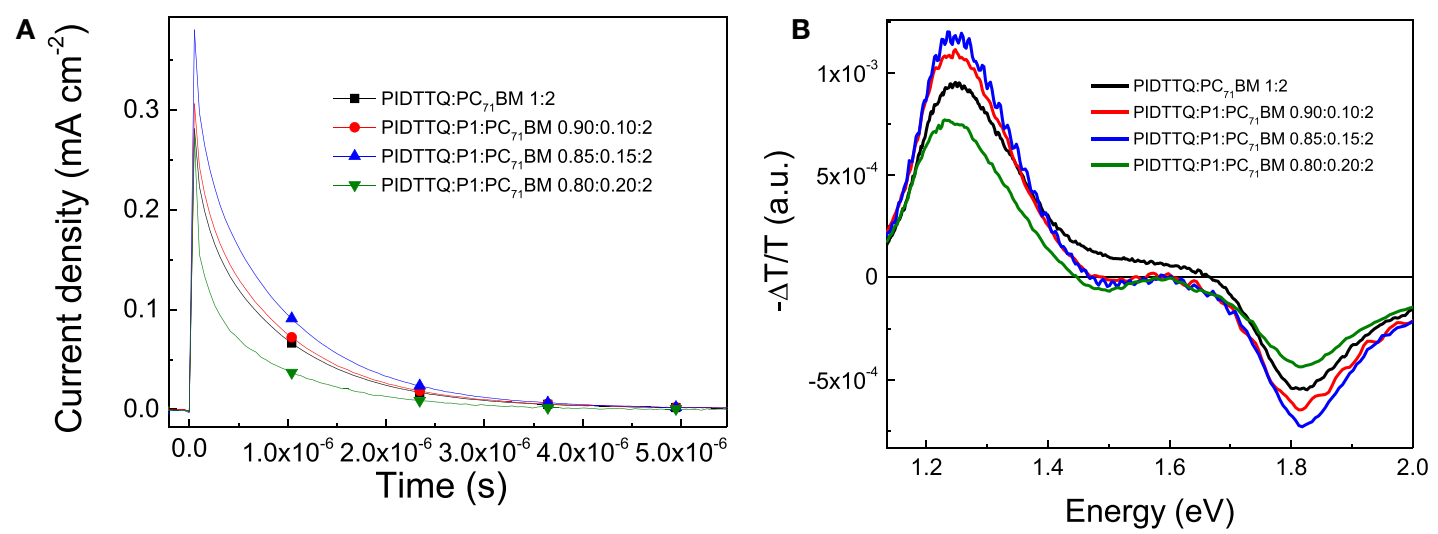

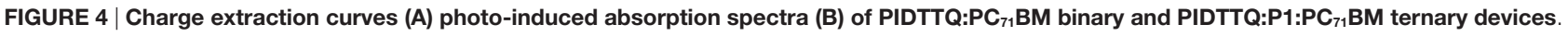


depicts the PIA spectra of binary and ternary devices measured at $60 \mathrm{~mW} \mathrm{~cm}^{-2}$ pump intensity at $10 \mathrm{~K}$. All spectra show a pronounced transmission minimum (bleach) around $1.81 \mathrm{eV}$ and a PIA feature around $1.24 \mathrm{eV}$. Contrary, the ternary blends show a novel bleaching feature around $1.58 \mathrm{eV}$. We associate the two transmission maxima at 1.81 and $1.58 \mathrm{eV}$ to the photobleaching of the electronic ground states of PIDTTQ and P1, respectively. As shown in Figure 4B, higher polaron signal is observed for the ternary PIDTTQ:P1:PC ${ }_{71} \mathrm{BM}$ (0.90:0.10:2), PIDTTQ:P1:PC ${ }_{71} \mathrm{BM}$ (0.85:0.15:2)-based devices compared with the binary cells, confirming the higher photogeneration ability by adding $10-15 \%$ of P1 into the host PIDTTQ:PC ${ }_{71} B M$ system.

\section{CONCLUSION}

In conclusion, we reported a novel ternary system with a clear contribution in the incident photon-to-current efficiency in the NIR region. A $J_{\text {sc }}$ improvement of around $20 \%$ was obtained for PIDTTQ:P1:PC ${ }_{71} \mathrm{BM}$ (0.85:0.15:2) ternary devices compared to PIDTTQ:PC ${ }_{71} \mathrm{BM}$ binary cells. However, the low FF limited the performances of the ternary $\mathrm{BHJ}$ solar cells. We studied the transport mechanism of the organic solar cells by employing photo-CELIV and TPV techniques. We found that by adding P1 into the host system of PIDTTQ:PC ${ }_{71} B M$ the $\mu \tau$ product is reduced, explaining the lower FFs. Despite the poorer transport properties, the complementary results of $\mathrm{CE}$ and PIA spectroscopy showed an improved charge generation in PIDTTQ:P1:PC ${ }_{71} \mathrm{BM}(0.85: 0.15: 2)$ ternary solar cells, leading to a PCE of more than $4.6 \%$.

\section{EXPERIMENTAL SECTION}

Materials and instruments: all reagents and starting materials were received from commercial suppliers and used without further purification. Anhydrous toluene was purchased from Sigma-Aldrich. Monomers M1 (Gasparini et al., 2015a) and M2 (Welch et al., 2013) were prepared according to literature procedures. The reactions were carried out under argon with standard and Schlenk techniques. Gel permeation chromatography (GPC) measurement was carried out at $135^{\circ} \mathrm{C}$ on a Waters Alliance 2000 GPC System equipped with PL-Guard and PL-mixed-B columns using trichlorobenzene as solvent. The UV spectrum was recorded on a Jasco V-670 spectrometer at room temperature. The HOMO energy level was determined by atmospheric pressure photoelectron spectroscopy using a photoelectron spectrometer model AC-2. The optical band gap was calculated using the formulae $\mathrm{Eg}=\mathrm{h}(\mathrm{c} / \lambda)+0.3 \mathrm{eV}$. Cyclic voltammetry was executed in chloroform with $0.1 \mathrm{M}(\mathrm{n}-\mathrm{Bu}) 4 \mathrm{NClO}_{4}$ against a standard calomel electrode. The electrochemical HOMO and LUMO energy levels were calculated using the formulae $\mathrm{HOMO}=-(\mathrm{Eox}+4.7) \mathrm{eV}$ and $\mathrm{LUMO}=-($ Ered +4.7$) \mathrm{eV}$, respectively.

\section{Fabrication of Photovoltaic Devices}

All devices were fabricated using doctor blading under ambient conditions with the structure of Figure 1A. Pre-structured ITO substrates were cleaned with acetone and isopropyl alcohol in an ultrasonic bath for $10 \mathrm{~min}$ each. After drying, the substrates were successively coated with $40 \mathrm{~nm}$ of zinc oxide $(\mathrm{ZnO})$, $10 \mathrm{~nm}$ of $\mathrm{Ba}(\mathrm{OH})_{2}$, and finally a 80 - to 90 -nm-thick active layer based on PIDTTQ:PC ${ }_{71} B M$ and PIDTTQ:P1:PC ${ }_{71} B M$ $\left(20 \mathrm{~g} \mathrm{~L}^{-1}\right)$. To complete the fabrication of the devices $10 \mathrm{~nm}$ of MoOx and $100 \mathrm{~nm}$ of Ag were thermally evaporated through a mask (with a $10.4 \mathrm{~mm}^{2}$ active area opening) under a vacuum of $\sim 2 \times 10^{-6}$ mbar.

\section{Nuclear Magnetic Resonance (NMR)}

${ }^{1} \mathrm{H}-\mathrm{NMR}$ and ${ }^{13} \mathrm{C}-\mathrm{NMR}$ measurements were carried out in $\mathrm{CDCl}_{3}$ solutions on a BruckerAVANCE III 600 spectrometer using a resonance frequency of ${ }^{1} \mathrm{H}-250 \mathrm{MHz}$. The NMR system was controlled by the TopSpin 2.1 software by Bruker (Figure S2 in Supplementary Material).

\section{Thermogravimetric Analysis}

Thermogravimetric analysis measurements were performed on a Perkin-Elmer Pyris Diamond TG/DTA. Samples of approximately $5 \mathrm{mg}$ were heated in air from 25 to $9^{\circ} \mathrm{C}$, at a rate of $5^{\circ} \mathrm{C} /$ $\min$.

\section{Cyclic Voltammetry (CV)}

Cyclic voltammetry studies were performed using a standard three-electrode cell. A platinum disk electrode was used as working electrode, a platinum wire as the counter electrode, and silver as the quasi-reference electrode. The oxidation and reduction potentials were calibrated against a ferrocene/ferrocenium $(\mathrm{Fc} /$ $\mathrm{Fc}^{+}$) redox couple, then they were referenced against saturated calomel electrode. Tetrabutylammonium perchlorate (TBAP; 99\%) was used as supporting electrolyte. Measurements were recorded using a PAR potensiostat/galvanostat Model VersaSTAT4, which was connected to a personal computer running the VersaStudio software version 2.44. In a typical experiment, around $2 \mathrm{mg}$ of the material was diluted in chloroform in the presence of $0.1 \mathrm{M}$ TBAP. The cyclic voltammetry graphs were recorded at a potential scan rate of $100 \mathrm{mV} \mathrm{s}^{-1}$ under argon atmosphere at $25^{\circ} \mathrm{C}$.

\section{$J-V$ Measurements}

The $J-V$ characteristics were measured using a source measurement unit from BoTest. Illumination was provided by a solar simulator (Oriel Sol 1A, from Newport) with AM1.5G spectrum at $100 \mathrm{~mW} / \mathrm{cm}^{2}$. UV-VIS absorption was performed on a Lambda 950, from Perkin Elmer. EQEs were measured using an integrated system from Enlitech, Taiwan. In order to study the light intensity dependence of current density, we used a series of neutral color density filters. The intensity of light transmitted through the filter was independently measured via a power meter. All the devices were tested in ambient air.

\section{Photo-CELIV}

In photo-CELIV measurements, the devices were illuminated with a 405-nm laser diode. Current transients were recorded across an internal $50 \Omega$ resistor of an oscilloscope (Agilent Technologies DSO-X 2024A). We used a fast electrical switch to isolate the cell and prevent CE or sweep out during the laser pulse and the td. After a variable td, a linear extraction ramp is applied via a function generator. The ramp, which was $20-\mu$ s long and $2 \mathrm{~V}$ 
in amplitude, was set to start with an offset matching the $V_{\mathrm{oc}}$ of the cell for each $t d$.

\section{TPV and CE Measurements}

A 405-nm laser diode was settled for keeping the solar cells in approximately $V_{\text {oc }}$ condition. Driving the laser intensity with a waveform generator Agilent 33500B and measuring the light intensity with a highly linear photodiode allowed to reproducibly adjust the light intensity with an error below $0.5 \%$ over a range of 0.2-4 suns. A small perturbation was induced with a second $405 \mathrm{~nm}$ laser diode driven by a function generator from Agilent. The intensity of the short ( $50 \mathrm{~ns}$ ) laser pulse was adjusted to keep the voltage perturbation below $10 \mathrm{mV}$, typically at $5 \mathrm{mV}$. After the pulse, the voltage decays back to its steady state value in a single exponential decay. The characteristic decay time was determined from a linear fit to a logarithmic plot of the voltage transient and returned the small perturbation charge carrier lifetime. In CE measurements, a 405-nm laser diode illuminated the solar cell for $200 \mu$ s, which was sufficient to reach a constant open-circuit voltage with steady state conditions. At the end of the illumination period, an analog switch was triggered that switched the solar cell from open-circuit to short-circuit ( $50 \Omega$ ) conditions within less than $50 \mathrm{~ns}$.

\section{Photoinduced Absorption}

Photoinduced absorption studies were performed by exciting the sample with a $405-\mathrm{nm}$ laser while simultaneously probing the sample with a white lamp. The PIA spectra of the sample were dispersed by a 1,200 lines/mm grating monochromator (iHR320) and detected by a silicon detector through lock-in technique.

\section{Atomic Force Microscopy}

Atomic force microscopy measurements were performed on a solver nano from NT-MDT using $300 \mathrm{kHz}$ single crystal silicon cantilevers (Nt-MDT, NSG30).

\section{REFERENCES}

Ameri, T., Dennler, G., Lungenschmied, C., and Brabec, C. J. (2009). Organic tandem solar cells: a review. Energy Environ. Sci. 2, 347. doi:10.1039/b817952b

Ameri, T., Li, N., and Brabec, C. J. (2013a). Highly efficient organic tandem solar cells: a follow up review. Energy Environ. Sci. 6, 2390-2413. doi:10.1039/ c3ee $40388 \mathrm{~b}$

Ameri, T., Khoram, P., Min, J., and Brabec, C. J. (2013b). Organic ternary solar cells: a review. Adv. Mater. 25, 4245-4266. doi:10.1002/adma.201300623

Cheng, P., Li, Y., and Zhan, X. (2014). Efficient ternary blend polymer solar cells with indene-C60 bisadduct as an electron-cascade acceptor. Energy Environ. Sci. 7, 2005. doi:10.1039/c3ee44202k

Cheng, P., Yan, C., Wu, Y., Wang, J., Qin, M., An, Q., et al. (2016). Alloy acceptor: superior alternative to PCBM toward efficient and stable organic solar cells. Adv. Mater. 28, 8021-8028. doi:10.1002/adma.201602067

Clarke, T. M., Lungenschmied, C., Peet, J., Drolet, N., and Mozer, A. J. (2015). A comparison of five experimental techniques to measure charge carrier lifetime in polymer/fullerene solar cells. Adv. Energy Mater. 5, 1401345. doi:10.1002/ aenm.201401345

Gasparini, N., Jiao, X., Heumueller, T., Baran, D., Matt, G. J., Fladischer, S., et al. (2016). Designing ternary blend bulk heterojunction solar cells with reduced carrier recombination and a fill factor of 77\%. Nat. Energy 1, 16118. doi:10.1038/ nenergy.2016.118

\section{AUTHOR CONTRIBUTIONS}

NG, TA, and CB conceived and developed the ideas. NG designed the experiments and performed device fabrication, electrical characterization, and data analysis. NG performed photo-CELIV, TPV, CE, and PIA measurements. AG-R synthesized the polymer under the supervision of AK, AA, GP, VG, CC, SA, US, SB, and AP-C performed CV measurements. NG and MP performed PL measurements and contributed to revision the manuscript. The projects were supervised by TA and CB.

\section{ACKNOWLEDGMENTS}

This project has received funding from the European Community's Seventh Framework Programme (FP7/2007-2013) under the Grant Agreement no 607585 project OSNIRO. In addition, this project has received funding from the European Community's Seventh Framework Programme (FP7/2007-2013) under the Grant Agreement no. 331389. CC acknowledges the financial support of a Marie Curie Intra European Fellowship (FP7PEOPLE-2012-IEF) project ECOCHEM. GP would like to thank the Ministry of Education and Religious Affairs in Greece for the financial support of this work provided under the co-operational program "AdvePol: E850." The authors gratefully acknowledge the support of the Cluster of Excellence "Engineering of Advanced Materials" at the University of Erlangen-Nuremberg, which is funded by the German Research Foundation (DFG) within the framework of its "Excellence Initiative," Synthetic Carbon Allotropes (SFB953) and Solar Technologies go Hybrid (SolTech).

\section{SUPPLEMENTARY MATERIAL}

The Supplementary Material for this article can be found online at http://journal.frontiersin.org/article/10.3389/fenrg.2016.00040/ full\#supplementary-material.

Gasparini, N., Katsouras, A., Prodromidis, M. I., Avgeropoulos, A., Baran, D., Salvador, M., et al. (2015a). Photophysics of molecular-weight-induced losses in indacenodithienothiophene-based solar cells. Adv. Funct. Mater. 25, 4898-4907. doi:10.1002/adfm.201501062

Gasparini, N., Salvador, M., Fladischer, S., Katsouras, A., Avgeropoulos, A., Spiecker, E., et al. (2015b). An alternative strategy to adjust the recombination mechanism of organic photovoltaics by implementing ternary compounds. Adv. Energy Mater. 5, 1501527. doi:10.1002/aenm.201570132

Gedefaw, D., Tessarolo, M., Prosa, M., Bolognesi, M., Henriksson, P., Zhuang, W., et al. (2016). Induced photodegradation of quinoxaline based copolymers for photovoltaic applications. Sol. Energy Mater. Sol. Cells 144, 150-158. doi:10.1016/j.solmat.2015.08.015

Goh, T., Huang, J.-S., Yager, K. G., Sfeir, M. Y., Nam, C.-Y., Tong, X., et al. (2016). Quaternary organic solar cells enhanced by cocrystalline squaraines with power conversion efficiencies $>10 \%$. Adv. Energy Mater 6, 1600660. doi:10.1002/ aenm. 201600660

Hamilton, R., Shuttle, C. G., O’Regan, B., Hammant, T. C., Nelson, J., Durrant, J. R., et al. (2010). Recombination in annealed and nonannealed polythiophene/ fullerene solar cells: transient photovoltage studies versus numerical modeling. J. Phys. Chem. Lett. 1, 1432-1436. doi:10.1021/jz1001506

He, Z., Xiao, B., Liu, F., Wu, H., Yang, Y., Xiao, S., et al. (2015). Single-junction polymer solar cells with high efficiency and photovoltage. Nat. Photonics 9, 174-179. doi:10.1038/nphoton.2015.6 
Heumueller, T., Burke, T. M., Mateker, W. R., Sachs-Quintana, I. T., Vandewal, K., Brabec, C. J., et al. (2015). Disorder-induced open-circuit voltage losses in organic solar cells during photoinduced burn-in. Adv. Energy Mater. 5, 150011. doi:10.1002/aenm.201500111

Holliday, S., Ashraf, R. S., Wadsworth, A., Baran, D., Yousaf, S. A., Nielsen, C. B., et al. (2016). High-efficiency and air-stable P3HT-based polymer solar cells with a new non-fullerene acceptor. Nat. Commun. 7, 11585. doi:10.1038/ ncomms 11585

Huang, J., Carpenter, J. H., Li, C.-Z., Yu, J.-S., Ade, H., and Jen, A. K. (2016). Highly efficient organic solar cells with improved vertical donor-acceptor compositional gradient via an inverted off-center spinning method. Adv. Mater. 28, 967-974. doi:10.1002/adma.201504014

Itskos, G., Othonos, A., Rauch, T., Tedde, S. F., Hayden, O., Kovalenko, M. V., et al. (2011). Optical properties of organic semiconductor blends with near-infrared quantum-dot sensitizers for light harvesting applications. Adv. Energy Mater. 1, 802-812. doi:10.1002/aenm.201100182

Ke, L., Min, J., Adam, M., Gasparini, N., Hou, Y., Perea, J. D., et al. (2016). A series of pyrene-substituted silicon phthalocyanines as near-IR sensitizers in organic ternary solar cells. Adv. Energy Mater. 6, 1502355. doi:10.1002/aenm.201502355

Keawsongsaeng, W., Gasiorowski, J., Denk, P., Oppelt, K., Apaydin, D. H., Rojanathanes, R., et al. (2016). Systematic investigation of porphyrin-thiophene conjugates for ternary bulk heterojunction solar cells. Adv. Energy Mater. 6, 1600957. doi:10.1002/aenm.201600957

Lee, T. H., Uddin, M. A., Zhong, C., Ko, S.-J., Walker, B., Kim, T., et al. (2016). Investigation of charge carrier behavior in high performance ternary blend polymer solar cells. Adv. Energy Mater. 6, 1600637. doi:10.1002/aenm.201600637

Li, N., Baran, D., Forberich, K., Machui, F., Ameri, T., Turbiez, M., et al. (2013). Towards 15\% energy conversion efficiency: a systematic study of the solution-processed organic tandem solar cells based on commercially available materials. Energy Environ. Sci. 6, 3407-3413. doi:10.1039/c3ee42307g

Liu, Y., Zhao, J., Li, Z., Mu, C., Ma, W., Hu, H., et al. (2014). Aggregation and morphology control enables multiple cases of high-efficiency polymer solar cells. Nat. Commun. 5, 5293. doi:10.1038/ncomms6293

Löslein, H., Ameri, T., Matt, G. J., Koppe, M., Egelhaaf, H. J., Troeger, A., et al. (2013). Transient absorption spectroscopy studies on polythiophene-fullerene bulk heterojunction organic blend films sensitized with a low-bandgap polymer. Macromol. Rapid Commun. 34, 1090-1097. doi:10.1002/marc. 201300354

Lu, L., Chen, W., Xu, T., and Yu, L. (2015a). High-performance ternary blend polymer solar cells involving both energy transfer and hole relay processes. Nat. Commun. 6, 7327. doi:10.1038/ncomms8327

Lu, L., Kelly, M. A., You, W., and Yu, L. (2015b). Status and prospects for ternary organic photovoltaics. Nat. Photonics 9, 491-500. doi:10.1038/nphoton.2015.128

Lu, L., Zheng, T., Wu, Q., Schneider, A. M., Zhao, D., Yu, L., et al. (2015c). Recent advances in bulk heterojunction polymer solar cells. Chem. Rev. 115, 12666-12731. doi:10.1021/acs.chemrev.5b00098

Lu, L., Xu, T., Chen, W., Landry, E. S., and Yu, L. (2014). Ternary blend polymer solar cells with enhanced power conversion efficiency. Nat. Photonics 8, 716-722. doi:10.1038/nphoton.2014.172

Min, J., Luponosov, Y. N., Gasparini, N., Xue, L., Drozdov, F. V., Peregudova, S. M., et al. (2015). Integrated molecular, morphological and interfacial engineering towards highly efficient and stable solution-processed small molecule solar cells. J. Mater. Chem. A 3, 22695-22707. doi:10.1039/C5TA06706E

Mozer, A. J., Sariciftci, N. S., Lutsen, L., Vanderzande, D., Österbacka, R., Westerling, M., et al. (2005). Charge transport and recombination in bulk heterojunction solar cells studied by the photoinduced charge extraction in linearly increasing voltage technique. Appl. Phys. Lett. 86, 112104. doi:10.1063/ 1.1882753
Nian, L., Gao, K., Liu, F., Kan, Y., Jiang, X., Liu, L., et al. (2016). 11\% efficient ternary organic solar cells with high composition tolerance via integrated near-IR sensitization and interface engineering. Adv. Mater. 28, 8184-8190. doi:10.1002/adma.201602834

Salvador, M., MacLeod, B. A., Hess, A., Kulkarni, A. P., Munechika, K., Chen, J. I. L., et al. (2012). Electron accumulation on metal nanoparticles in plasmon-enhanced organic solar cells. ACS Nano 6, 10024-10032. doi:10.1021/ nn303725v

Shuttle, C. G., O’Regan, B., Ballantyne, A. M., Nelson, J., Bradley, D. D. C., De Mello, J., et al. (2008). Experimental determination of the rate law for charge carrier decay in a polythiophene: fullerene solar cell. Appl. Phys. Lett. 92, 90-93. doi:10.1063/1.2891871

Spyropoulos, G. D., Kubis, P., Li, N., Baran, D., Lucera, L., Salvador, M., et al. (2014). Flexible organic tandem solar modules with $6 \%$ efficiency: combining roll-toroll compatible processing with high geometric fill factors. Energy Environ. Sci. 7, 3284-3290. doi:10.1039/C4EE02003K

Spyropoulos, G. D., Ramirez Quiroz, C. O., Salvador, M., Hou, Y., Gasparini, N., Schweizer, P., et al. (2016). Organic and perovskite solar modules innovated by adhesive top electrode and depth-resolved laser patterning. Energy Environ. Sci. 9, 2302-2313. doi:10.1039/C6EE01555G

Squeo, B. M., Gasparini, N., Ameri, T., Palma-Cando, A., Allard, S., Gregoriou, V., et al. (2015). Ultra low band gap $\alpha, \beta$-unsubstituted BODIPY-based copolymer synthesized by palladium catalyzed cross-coupling polymerization for near infrared organic photovoltaics. J. Mater. Chem. A 3, 16279-16286. doi:10.1039/ C5TA04229A

Welch, G. C., Bakus, R. C., Teat, S. J., and Bazan, G. C. (2013). Impact of regiochemistry and isoelectronic bridgehead substitution on the molecular shape and bulk organization of narrow bandgap chromophores. J. Am. Chem. Soc. 135, 2298-2305. doi:10.1021/ja310694t

Yang, Y. M., Chen, W., Dou, L., Chang, W., Duan, H., Bob, B., et al. (2015). Highperformance multiple-donor bulk heterojunction solar cells. Nat. Photonics 9 , 190-198. doi:10.1038/nphoton.2015.9

You, J., Dou, L., Yoshimura, K., Kato, T., Ohya, K., Moriarty, T., et al. (2013). A polymer tandem solar cell with $10.6 \%$ power conversion efficiency. Nat. Commun 4, 1446. doi: $10.1038 /$ ncomms 2411

Zhang, J., Zhang, Y., Fang, J., Lu, K., Wang, Z., Ma, W., et al. (2015). Conjugated polymer-small molecule alloy leads to high efficient ternary organic solar cells. J. Am. Chem. Soc. 137, 8176-8183. doi:10.1021/jacs. 5 b03449

Zhang, Q., Kan, B., Liu, F., Long, G., Wan, X., Chen, X., et al. (2014). Small-molecule solar cells with efficiency over 9\%. Nat. Photonics 9, 35-41. doi:10.1038/ nphoton.2014.269

Zhao, W., Qian, D., Zhang, S., Li, S., Inganäs, O., Gao, F., et al. (2016). Fullerene-free polymer solar cells with over $11 \%$ efficiency and excellent thermal stability. Adv. Mater. 28, 4734-4739. doi:10.1002/adma.201600281

Conflict of Interest Statement: The authors declare that the research was conducted in the absence of any commercial or financial relationships that could be construed as a potential conflict of interest.

Copyright (C) 2017 Gasparini, García-Rodríguez, Prosa, Bayseç, Palma-Cando, Katsouras, Avgeropoulos, Pagona, Gregoriou, Chochos, Allard, Scherf, Brabec and Ameri. This is an open-access article distributed under the terms of the Creative Commons Attribution License (CC BY). The use, distribution or reproduction in other forums is permitted, provided the original author(s) or licensor are credited and that the original publication in this journal is cited, in accordance with accepted academic practice. No use, distribution or reproduction is permitted which does not comply with these terms. 